\title{
Pluralismo, pós-estruturalismo e "gerencialismo engajado": os limites do movimento critical management studies
}

\section{Pluralism, post-structuralism and "engagement management": limits for the critical management studies movement}

\author{
Ana Paula Paes de Paula ${ }^{1}$ \\ Carolina Machado Saraiva de Albuquerque Maranhão² \\ Amon Narciso de Barros ${ }^{3}$
}

\section{Resumo}

0 objetivo deste artigo é questionar o pluralismo do movimento critical management studies (CMS), apontar os limites do pós-estruturalismo como epistemologia crítica, denunciar os riscos de uma crítica alinhada com o "gerencialismo engajado" e apontar caminhos para o debate sobre a teoria e a prática no movimento crítico. Para isso, definimos as principais características do pós-estruturalismo, questionando seu caráter crítico, e problematizamos a questão do pluralismo no movimento CMS. Em seguida, analisamos como alguns dos representantes deste movimento defendem o "gerencialismo engajado" através de uma performatividade crítica, fazendo um uso inadequado de algumas formulações pósestruturalistas. Discutimos então os caminhos para a prática na crítica, resgatando o conceito de práxis e afirmando a importância da educação como forma de despertar consciências e reconstituir o ativismo social e político. Concluímos destacando que o pós-estruturalismo deveria ser resgatado com maior seriedade, de modo a se constituir um novo movimento teórico para abrigar suas contribuições, preservando o caráter crítico.

Palavras-chave: critical management studies; gerenciamento engajado; pós-estruturalismo; pluralismo.

\begin{abstract}
The aim of this article is to question pluralism in Critical Management Studies (CMS) movement, to point out the limits of the post-structuralism as a critical epistemology, to denounce the risks of a critique in line with "engagement management" and to show different ways to arrive at a debate between theory and practice on the critical movement. To do so, we described the most important post-structuralism characteristics, questioning the critical status of this epistemology and also questioning pluralism in CMS. Next, we discuss how some of CMS' representatives defend "engagement management" through a critical perfomativity which uses inadequately formulations of post-structuralism. We also discuss other practical approaches for a critique in organization studies, using the concept of praxis and critical education as ways to enlighten consciences and reestablish a critical activism. We conclude that post-structuralism should be taken more seriously, what may indicate that is necessary to build a new theoretical movement to use its contributions, preserving its critical character.
\end{abstract}

Key words: critical management studies; engagement management; post-structuralism; pluralism.

\footnotetext{
${ }^{1}$ Pós-Doutora em Administração pela Escola de Administração do Empresas de São Paulo da Fundação Getulio Vargas (EAESP/FGV) e Doutora em Ciências Sociais pelo Instituto de Filosofia e Ciências Humanas da -Universidade Estadual de Campinas (IFCH/UNICAMP). Professora adjunta do Centro de Pós-Graduação e Pesquisas em Administração da Universidade Federal de Minas Gerais. Endereço: Av. Antônio Carlos, 6.627 - Campus Pampulha - Faculdade de Ciências Econômicas CEPEAD Belo Horizonte - Minas Gerais - Brasil - CEP: 31270-901. E-mail: appaula@face.ufmg.br

${ }^{2}$ Doutoranda bolsista da CAPES - Centro de Pós-Graduação e Pesquisas em Administração - Universidade Federal de Minas Gerais-UFMG. Mestre em Administração. Endereço: R. Santo Agostinho, 567 apt 1001 - Sagrada Família - Belo Horizonte -Minas Gerais - Brasil - CEP: 31035-480. E-mail: carola.maranhao@gmail.com

${ }^{3}$ Doutorando bolsista da Fundação de Amparo à Pesquisa do Estado de Minas Gerais/FAPEMIG no Centro de Pós-Graduação e Pesquisas em Administração da Universidade Federal de Minas Gerais - UFMG. Mestre em Administração. Endereço: Av. do Contorno, 3999 - apt. 04. Santa Efigênia - Belo Horizonte - MG Brasil - CEP: 30110-060. E-mail: amonbarros@gmail.com
} 


\section{Introdução}

Em um debate recente sobre os estudos críticos, promovido pela Revista de Administração Contemporânea, Misoczky e Amantino-De-Andrade (2005a) fazem uma crítica da noção de microemancipação apresentada por Alvesson e Willmott (1992a), afirmando que o movimento critical management studies (CMS) realiza uma crítica domesticada, uma vez que restringe a amplitude das possibilidades emancipatórias. Alcadipani (2005) responde dizendo que esse é um movimento plural, com predominância de perspectivas pós-estruturalistas que defendem a microemacipação, pois não considera ser possível uma emancipação ampliada diante do contexto pós-moderno, que contesta as grandes narrativas e as perspectivas de revolução. As autoras, por sua vez, respondem com o artigo "Quem tem medo do fazer acadêmico como práxis?" (MISOCZKY; AMANTINODE-ANDRADE, 2005b), questionando os riscos desse pluralismo, que consideram ser também uma ideologia, na medida em que relativiza a legitimidade das contestações. Na visão das autoras, a principal tarefa política contemporânea seria justamente o questionamento desse pluralismo, de modo que os intelectuais não deveriam fugir às responsabilidades políticas, tornando o fazer acadêmico uma práxis.

Esse instigante debate, que coloca em pauta os rumos do movimento CMS, serviu-nos como ponto de partida para este artigo. As críticas ao movimento estão se avolumando e acreditamos que esse questionamento é uma oportunidade para que haja uma reflexão sobre o status da crítica na comunidade acadêmica na área de estudos organizacionais. É fato que existem diversas abordagens para desenvolvê-la, pois há diferenças sensíveis entre o marxismo clássico, a teoria crítica frankfurtiana e o pós-estruturalismo. Também é verdadeiro que um movimento intelectual que se opõe ao mainstream deve procurar se fortalecer ao invés de fragmentar-se. No entanto, isso não quer dizer que críticas não devam ser dirigidas aos caminhos que essas abordagens vêm tomando, especialmente, a pós-estruturalista. Em continuidade ao nosso trabalho sobre a tradição crítica brasileira, debruçamo-nos sobre o movimento CMS com o objetivo de distingui-lo do movimento brasileiro. Para isso, realizamos uma pesquisa que envolveu leituras sistemáticas da produção intelectual dos principais representantes do CMS, bem como entrevistas com os mesmos na Inglaterra, realizadas em janeiro de 2008. Os resultados estão nos permitindo realizar algumas constatações que vão além dos nossos objetivos iniciais e que, acreditamos, possam contribuir para a evolução do conhecimento no campo.

A primeira constatação revela que o pluralismo do movimento critical management studies é de fato uma característica marcante do mesmo, pois em nossa pesquisa pudemos averiguar a diversidade de streams nas conferências bianuais, bem como a multiplicidade de abordagens epistemológicas na produção intelectual dos seus participantes. Além disso, nas já referidas entrevistas, ficou evidente que essa pluralidade é uma estratégia política para fortalecer o movimento. Isso não deixa de ser inquietante, pois se por um lado é uma decisão democrática, por outro, não deixa de colocar em questão o fato de que tal multiplicidade amplia demais o escopo da crítica, afetando sua própria identidade.

A segunda constatação evidencia uma clara predominância do pós-estruturalismo no movimento CMS, o que reforça esse caráter plural, visto que essa abordagem teórica é adepta do relativismo e de algumas outras premissas do pós-modernismo. A terceira constatação mostra que a questão da teoria e da prática fundamental para qualquer movimento crítico - vem assumindo, no discurso de alguns dos representantes do CMS, contornos que resvalam em um questionável "gerencialismo engajado". Isso traz para a pauta de discussões as relações entre teoria e prática, bem como o questionamento sobre o que pode ser a prática quando se trata da crítica. Dessa forma, abre-se espaço tanto para o reconhecimento da importância da participação dos intelectuais na vida política (e os dilemas que isso representa) quanto para o entendimento da crítica como experiência formativa (ADORNO, 2003), estreitamente relacionada com a educação para a vida e para a cidadania. Rompe-se assim com as recentes visões tecnicistas de ensino, costumeiramente privilegiadas no campo da administração.

Tendo como referência essas constatações, elaboramos este artigo, que tem como objetivos questionar o pluralismo do CMS, apontar os limites do pós-estruturalismo como epistemologia crítica, denunciar os riscos de uma crítica alinhada com o "gerencialismo engajado" e apontar caminhos para o debate sobre a teoria e a prática no movimento crítico. Para isso, na primeira seção, definimos as principais características do pós- 
estruturalismo, questionando o caráter crítico dessa epistemologia, e problematizamos a questão do pluralismo no movimento CMS, apontando que o mesmo pode ter dois significados: a) uma multiplicidade epistemológica que ajuda a preservar o próprio movimento; ou b) um descompromisso com o projeto da crítica, através de um "gerencialismo engajado". Na segunda seção, analisamos como alguns dos representantes do CMS defendem o "gerencialismo engajado" através de uma "performatividade crítica", fazendo um uso inadequado de algumas formulações pós-estruturalistas. Na terceira seção, discutimos alguns caminhos para a prática na crítica, resgatando o conceito de práxis e afirmando a importância da educação como forma de despertar consciências e reconstituir o ativismo social e político. Nas conclusões, sintetizamos algumas elaborações realizadas no artigo e frisamos que o pós-estruturalismo deveria ser resgatado com mais seriedade, de modo que talvez seja necessário constituir um novo movimento teórico para abrigar suas contribuições, preservando seu caráter crítico.

\section{0 pluralismo do pós-estruturalismo no CMS}

Definir o pós-estruturalismo em algumas poucas linhas não faz justiça à complexidade dessa epistemologia. Mesmo assim tentaremos traçar, pelo menos, seus aspectos gerais, visto que isso é fundamental para a compreensão do movimento CMS. Em primeiro lugar, é fundamental dizer que o pós-modernismo e o pósestruturalismo são movimentos distintos, tanto nas raízes filosóficas, quanto nas intenções, embora, partilhem de algumas elaborações: o primeiro se refere a uma ruptura com o modernismo, a um estilo e mesmo a uma ideologia, enquanto o segundo, embora, também coloque em questão a modernidade, procura dar uma resposta ao estruturalismo, superando algumas de suas premissas, mas preservando outras.

O pós-estruturalismo rompe com o modernismo, na medida em que descarta qualquer tipo de razão, eliminando o critério de explicação que distingue entre o nu e o mascarado, entre a teoria e a ideologia: no limite, como tudo é relativo, tudo é justificável, não sendo mais possível identificar o que pode ser considerado dominação ou emancipação. Para Habermas (1990), esse rompimento torna a crítica impossível, pois destrói as normas constitutivas da modernidade (verdade, racionalidade e liberdade), que viabilizam a crítica. O pósestruturalismo se diferencia do estruturalismo porque faz uma tentativa de resgatar a história, que foi apagada por essa tradição teórica por sua análise sincrônica das estruturas. No entanto, o pós-estruturalismo defende a mesma noção de sujeito do estruturalismo, uma vez que critica o sujeito como um ser autônomo, livre e autoconsciente, elaboração que é típica do humanismo, da fenomenologia, da teoria crítica e do existencialismo. No seu lugar, apresenta um sujeito descentrado e dependente do sistema linguístico, concebido em termos relacionais, construído discursivamente e governado por estruturas e sistemas mediados por forças libidinais e práticas histórico-culturais.

Devido a esse posicionamento, os pós-estruturalistas contribuem para que exista certa descrença na potencialidade do sujeito, no âmbito individual ou coletivo, já que este está condicionado por estruturas préexistentes. Grandes esforços são despendidos pelos teóricos desse campo para afirmar e apontar as evidências da "morte do sujeito" ou do seu descentramento. Ao mesmo tempo, conforme aponta McGushin (2005), justamente, por causa desse posicionamento, esse conceito é tão discutido e desenvolvido. Afinal, mesmo apontado como descentrado, cooptado pelas estruturas e fragmentado, o homem continua sendo o produtor de sua realidade social, seja ele considerado sujeito ou um aglomerado de fragmentos.

O pós-estruturalismo também abandona o pensamento hegeliano em favor do pensamento nietzscheano, o qual opõe o "jogo da diferença" ao "trabalho da dialética". O "jogo da diferença" defende que a utilização das oposições binárias para o entendimento de identidades políticas - como nós/eles, cidadãos/não-cidadãos, legítimo/ilegítimo - resulta na exclusão de certos grupos culturais e sociais. Nesse sentido, o conceito de "diferença" proporcionaria uma "lógica" mais apropriada para se compreender as lutas pela identidade, pois deixa de definir o jogo histórico em termos de dicotomias que implicam exclusões. Assim, "o jogo da diferença" inaugura uma nova forma de filosofar, um novo pensamento crítico que não é baseado no marxismo nem na dialética. 
Com isso se definem os críticos "modernos" que seguem a tradição hegeliana e marxista, baseando-se no "trabalho da dialética", e os críticos "pós-modernos" (ou melhor, "pós-estruturalistas"), que seguem a tradição nietzscheana, baseando-se no "jogo da diferença". O problema é que essa busca por uma nova forma de filosofar e criticar está pontuada por limites, pois ao se negar os dualismos, rompe-se com as bases fundamentais da crítica (HABERMAS, 1990) feita justamente a partir dos contrastes, pois não é possível enxergar as diferenças sem primeiro ver os pólos (D'AGOSTINI, 2002). O "jogo da diferença" tem como pressuposto o "trabalho da dialética" e não é verdadeiro que a dialética não concebe a pluralidade de mundos, uma vez que é possível integrar a diferença na dialética. Isso coloca em questão o pós-estruturalismo como base epistemológica crítica e implica, talvez, a fundação de um novo movimento teórico que incorpore as contribuições do pós-estruturalismo, mas preserve o caráter crítico.

Alvesson e Willmott (1992b, 1993) estão entre os fundadores do movimento CMS e podemos afirmar que foram responsáveis pela unificação da análise das organizações em uma perspectiva crítica, que vinha sendo realizada, no período de 1979-1990, por estudiosos das organizações, inspirados pelo pensamento marxista e pela sociologia do trabalho. Cabe aqui observar que alguns desses autores se adiantaram no tratamento desses estudos como critical management, como é o caso de Forester (1983) e de Steffy e Grimes (1985). De acordo com Hassard (2001), o CMS foi constituído por autores filiados à labor process theory (LPT) que adotaram uma nova posição. Originalmente, a LPT partiu das formulações de Braverman, sofrendo críticas tanto dos neomarxistas quanto dos pós-estruturalistas (JAROS, 2005; PARKER, 1999), que buscaram reposicioná-la do ponto de vista teórico. Isso gerou embates em torno da renovação da LPT entre os pós-estruturalistas David Knights e Hugh Willmott e um grupo de pesquisadores britânicos neomarxistas, como Chris Smith, Paut Thompson e Stephen Ackroyd.

De acordo com Parker (1999), tanto Smith e Thompson (1992) quanto Thompson e Ackroyd (1995) acusam Knights e Willmott de se afastarem das bases marxistas da LPT, alinhando-se com a epistemologia pósestruturalista que coloca em questão dualismos que são essenciais para a análise do trabalho nas organizações (como por exemplo estrutura e agência) e de dificultarem a articulação de posições políticas em decorrência de uma desqualificação das bases de julgamento ético. Knights (1995) responde, criticando os dualismos e argumenta que o pós-estruturalismo não significa o fim da política, mas sua substituição por práticas locais mais modestas e reflexivas. Willmott (1995) reconhece a impossibilidade de realizar o trabalho intelectual sem contradições, mas alerta para o risco de sua radicalização, admitindo que tenha se afastado das bases marxistas, embora acredite que o pós-estruturalismo se coadune com a abordagem dialética. Parker $(1995,1999)$, por sua vez, identifica dualismos no próprio discurso de Knights e Willmott e assume uma posição humanista, argumentando que o pós-dualismo pós-estruturalista não resolve a questão do sujeito e cria uma nova "gaiola de ferro", pois não acredita que o sujeito seja capaz de se libertar das armadilhas do poder e emancipar-se.

Em relação a Knights, não há dúvidas no que diz respeito ao posicionamento pós-estruturalista mas quanto a Willmott, verificam-se contradições que merecem ser observadas Isso porque ele (O'DORHERTY; WILLMOTT, 2001; WILLMOTT, 1995) vê consistência entre o pós-estruturalismo e a dialética, bem como acredita que aquele seja uma via para resgatar a subjetividade e a resistência, superando o "desaparecimento do sujeito". Deve ser levado em conta que durante entrevista realizada, ao falar sobre sua produção acadêmica mais recente, revelou ter migrado para o pós-estruturalismo dos neomarxistas Ernesto Laclau e Chantal Mouffe, rompendo com uma trajetória iniciada na LPT e com as elaborações de Giddens. Já Parker revelou na entrevista uma descrença em relação aos posicionamentos epistemológicos, considerados elucubrações teóricas vãs diante das questões práticas da política, sugerindo assim algum grau de alienação quanto ao caráter ideológico dos mesmos e afastando-se de seu posicionamento anterior, que era mais próximo dos marcos da modernidade, movendo-se para o terreno do pós-estruturalismo.

Acreditamos que a multiplicidade de leituras do pós-estruturalismo seja uma das razões para a crescente pluralidade do movimento CMS. Essa epistemologia, que já guarda em si uma tolerância ao relativismo, pode servir de "porta de entrada" aos pesquisadores que não se comprometem com o projeto da crítica. É importante compreendermos que o pluralismo no CMS pode guardar dois significados: a) uma multiplicidade 
epistemológica que ajuda a preservar o próprio movimento CMS; b) um descompromisso com o projeto da crítica, através de um "gerencialismo engajado".

O primeiro significado é assumido por seus próprios representantes, como fica claro no artigo de Adler, Forbes e Willmott (2007). Eles apontam como correntes teóricas utilizadas no CMS as teorias estruturais orientadas para a regulação, a sociologia clássica, o marxismo e as teorias correlacionadas (o marxismo clássico, a labor process theory [LPT] e a Escola de Frankfurt), o pragmatismo e o interacionismo simbólico, o pósmodernismo, o feminismo e o ambientalismo. De um modo geral, esse ecletismo teórico garantiria o pluralismo do movimento, necessário para sua própria preservação, conforme constatamos na nossa pesquisa e que será discutido mais adiante.

Entre as premissas epistemológicas destacadas por Adler, Forbes e Willmott (2007) encontram-se:

a) a teoria do "standpoint" - adotada por aqueles que criticam a ideia da neutralidade do trabalho científico e acreditam que a subjetividade do pesquisador e a objetividade do lugar de pesquisa afetam os resultados da pesquisa;

b) o pós-estruturalismo - que critica a teoria do "standpoint", pregando o relativismo e rejeitando a noção de que os atores que ocupam uma dada posição na estrutura social têm interesse em comum, o que dá a eles uma perspectiva partilhada; e

c) o realismo crítico - que costuma ser adotado por aqueles que criticam o mainstream positivista, mas se incomodam com a excessiva dependência de valores da teoria do "standpoint" e com o relativismo ilógico da epistemologia pós-estruturalista.

Ainda de acordo com os autores, os principais projetos críticos do CMS envolvem a educação em gestão, o ativismo político e social e a relação com a prática gerencial cotidiana.

Nesse manifesto pluralismo, alguns elementos chamam atenção. Em primeiro lugar,,há aqui um ecletismo teórico que se distancia de uma abordagem prioritariamente crítica. Em segundo lugar, as premissas epistemológicas destacadas não incluem declaradamente uma epistemologia crítica, vinculada ao marxismo ou à teoria crítica. Finalmente, a prática gerencial cotidiana é paradoxalmente incluída como um projeto crítico, comprometendo o CMS com uma posição cujas implicações serão melhor discutidas na segunda seção deste artigo. Vale ainda notar que esse pluralismo costuma ser apresentado como uma manifestação de vigor do movimento CMS, sem uma discussão mais sistemática de suas consequências.

O segundo significado de pluralismo é o que estamos denominando neste artigo de "gerencialismo engajado". Esse gerencialismo advém de duas posturas: uma ingênua e uma astuta (conforme FREIRE, 1989). A postura ingênua é aquela derivada da compreensão de alguns dos principais pesquisadores do CMS de que a crítica em administração é um movimento político que deve incentivar o estabelecimento de parcerias entre diversas áreas de pesquisa que guardem entre si um mínimo de semelhança, a fim de fortalecer o movimento da crítica nos EUA e no Reino Unido, mesmo que isso signifique subestimar os riscos de tal empreitada.

A postura astuta é aquela em que os pesquisadores aproveitam-se da "brecha" estabelecida pela postura ingênua e pelo próprio pluralismo - marcadamente presente nas visões pós-modernas e nas coalizões políticas feitas - e desvirtuam o projeto da crítica, utilizando-a com vistas a uma melhoria da performance gerencial. Esse tipo de "crítica" é, na verdade, uma ação reformista que justifica suas atitudes reacionárias de manutenção do status quo alicerçando-se em falsos argumentos de imobilismo político e de fracasso das teorias revolucionárias. Essa "crítica" é instrumento de docilização das pessoas, pelo emprego de uma retórica de vanguarda teórica (porém, suja e cruel) que esconde seus reais propósitos políticos de acomodação das pessoas "em seus devidos lugares". Esse "gerencialismo engajado" e suas consequências serão discutidos na seção seguinte. 


\section{0 "gerencialismo engajado"}

No artigo "For management", Clegg et al (2006) fazem uma crítica equivocada ao movimento CMS, assumindo-o como predominantemente teórico crítico e clamando por sua aproximação do pós-estruturalismo, uma vez que defendem uma abordagem polifônica que abranja as diferenças e questione as grandes narrativas. Willmott (2006), responde a este artigo, coerentemente, argumentando que o CMS já defende esse tipo de abordagem, pois conforme o "manifesto do critical management studies", diversas tradições teóricas (inclusive, o pós-estruturalismo) são conclamadas a se unirem em favor da crítica.

No entanto, não é essa falha que se destaca nas elaborações de Clegg et al (2006), mas sim sua tentativa de se contrapor ao livro de Parker (2002) Against management, argumentando que ser crítico do management não significa ser contra o management. Parker (2006) responde de forma diplomática, perguntando o que está sendo considerado management, sugerindo que Clegg e seus co-autores estão utilizando a palavra management no lugar de "organização", de modo que não seriam a favor do management, mas a favor da organização e de toda a diversidade que a mesma implica.

Na postura de Parker ocorre um silenciamento que consideramos muito importante, pois ele deixa de colocar em questão o verdadeiro caráter do estudo de Clegg et al (2006), o qual aponta para um "gerencialismo engajado", postura que vem se revelando entre alguns seguidores do CMS. Questionando o caráter teórico do movimento crítico, esses autores aventam a possibilidade de ser "crítico" e ao mesmo termo ser "a favor do gerencialismo". Defendem então "possibilidades de engajamento e resistência dentro, mas não em oposição às iniciativas gerenciais". Aproximam-se assim de um ecletismo arriscado, na medida em que exploram a ideia de que é possível defender o gerencialismo sem defender os desejos tecnocráticos de "performatividade" (pediremos licença ao leitor para utilizar esse neologismo, por não encontrarmos expressão equivalente em português).

Esse mesmo posicionamento também aparece no artigo de Spicer, Alvesson e Kärreman (2007), “Critical performativity: the unfinished business of critical management studies", o qual defende que o CMS deve ser "profundamente performativo", sugerindo uma mudança no entendimento do significado de performatividade, além de apontar o conceito de "performatividade crítica" como uma direção mais construtiva para o CMS. À primeira vista, as intenções apontam para uma integração entre teoria e prática, bem como uma "virada política" no movimento, na medida em que os autores propõem que o CMS deva questionar radicalmente o management, desafiar o gerencialismo e reimaginar práticas gerenciais.

É interessante notar que Watson (2001), por exemplo, ao tomar como objeto de análise a atividade dos gerentes, não assume uma postura astuta quanto à questão performática que permeia as funções inerentes à posição ocupada por estes, pois admitiu em entrevista não ser um crítico, uma vez que defende a performatividade. Entretanto, o mesmo não ocorre com Clegg et al (2006) e com Spicer, Alvesson e Kärreman (2007), que parecem não ver problemas na defesa da performance como crítica, abandonando o conceito de práxis, caro à tradição marxista, em favor de um conceito gerencialista.

A linha de raciocínio de Spicer, Alvesson e Kärreman (2007) começa com um questionamento das características do CMS descritas por Fournier e Grey (2006), que abrangem a desnaturalização, a reflexividade e a desvinculação da performance. $\mathrm{O}$ argumento principal é que seria preciso compreender a performatividade como algo mais do que uma obsessão com a visão instrumental entre meios e fins, pois a ideia de performance não teria sido totalmente capturada pela rígida matriz de insumos e resultados. Fazem então uma crítica da antiperformatividade no CMS, defendendo que:

a) a maior parte da pesquisa do CMS na verdade é produzida com uma intenção performática, pois está vinculada ao produtivismo acadêmico;

b) a comunidade do CMS, assim como de outros intelectuais, vive confortavelmente dos resultados da performatividade na economia capitalista; 
c) o credo da antiperformatividade sabota a intenções do CMS de reconstruir o mundo social;

d) a ideia de antiperformatividade cria uma espécie de "consciência cínica";

e) o alinhamento do CMS com a antiperformatividade essencializa o campo em uma base negativa da crítica pela crítica; $\mathrm{e}$

f) a orientação antiperformance deixa o CMS de "calças curtas" para responder aos emergentes problemas sociais.

Spicer, Alvesson e Kärreman (2007) finalizam dizendo que a adesão a uma "performatividade crítica" seria uma forma de complementar a crítica, sem intenção de substituí-la.

Até este ponto, temos uma inteligente manobra desses três autores para tentar associar antiperformatividade a um comodismo e conveniência dos intelectuais, que na visão dos autores não refletem sobre sua própria posição e estariam se encastelando em suas "torres de marfim", mantendo a distância da vida política. No entanto, uma análise mais apurada dessa tentativa revela um conjunto de sofismas, especialmente, quando averiguamos do que se trata a reinvenção gerencial imaginada pelos autores, que é muito próxima de um "gerencialismo engajado". Isso porque, em primeiro lugar, Spicer, Alvesson e Kärreman (2007) sugerem que a "performatividade crítica" envolve um posicionamento afirmativo, descrito da seguinte maneira:

Isto significa que ao invés de estabelecer uma distância da prática gerencial, nós procuramos trabalhar o mais próximo possível dela. Ao fazer isso, podemos saber em que momento a prática permite elaborar ou criar potenciais libertários. Em vez de simplesmente rejeitar a oferta de práticas de gerenciamento como qualidade total ou "talent management" sem nem considerá-las, essa tática busca achar suas potencialidades. Nesse sentido, poderíamos apontar as "meditações" encontradas em um livro como $O$ zen e a arte da manutenção da motocicleta como um exemplo de alguém que levou a noção de qualidade realmente a sério e que, ao fazê-lo, transformou-a numa espécie de prática libertária. Desse modo, a crítica não deveria apenas trabalhar destruindo o discurso. Pelo contrário, ela deveria trabalhar através de uma reelaboração criativa, ativa e subversiva do discurso. Isso envolveria um processo de mudança radical da lógica gerencial, que a transformaria de dentro, ao invés de atacá-la de fora. (p.14, tradução livre)

Em segundo lugar, a "performatividade crítica" envolveria um posicionamento pragmático, uma espécie de "reforma revolucionária" que deveria transformar o management fazendo incisões incrementais em processos particulares. Esses dois posicionamentos se alinham com a ideia de uma microemancipação valorizada pelo pós-estruturalismo e defendida num trabalho de Alvesson e Willmott (1992a), que não por acaso é citado logo no início do artigo de Spicer, Alvesson e Kärreman (2007). Estabelece-se assim um equívoco que está se tornando comum no âmbito do CMS: utilizar a ideia de microemancipação para defender uma ação gerencial engajada, distorcendo a essência dessa proposição pós-estruturalista.

Ora, isso não deixa de ser uma contradição, em termos, visto que a ação gerencial, mesmo socialmente responsável, não rompe com a lógica instrumental, por mais que se ressignifique a idéia de performance. A "performatividade crítica" é amplamente questionável, pois conflita com a própria razão de ser do management e com a base material que o sustenta. Marcuse (2002) afirma, já em 1964, que, em essência, os objetivos da empresa capitalista não se alteram nem com a separação entre a posse e o gerenciamento, nem com a aquisição de ações por um maior número de proprietários e, acrescentamos, tampouco com um gerencialismo travestido de humanista. É o próprio Marcuse (1978) que aponta ser o "princípio de produtividade" um dos sustentáculos do sistema de dominação nesta sociedade. O gerente está fadado, assim como Ulisses, na análise de Adorno e Horkheimer (1985), a reproduzir a vida do opressor na sua própria vida, e não consegue mais escapar deste papel social, que consiste em reproduzir a dominação, mesmo de forma velada, posto que ele mesmo está alienado dessa condição.

Pode ser verdade que os intelectuais se beneficiem dos resultados do capitalismo, mas não podemos ignorar o fato de que são os gestores que exercem diretamente a exploração necessária para obter esses resultados. Por 
outro lado, não é possível ignorar o "reformismo conformado" de Spicer, Alvesson e Kärreman (2007). Ao argumentarem a possibilidade de numa "revolução gradual" esses autores deixam de fazer a crítica do sistema vigente, reduzindo as possibilidades de transformação a uma escala micro, desconsiderando assim os limites estruturais que isso impõe a uma emancipação num sentido mais amplo e descartando conceitos como ideologia e alienação.

Esse "reformismo conformado" de Spicer, Alvesson e Kärreman (2007) fica ainda mais evidente quando eles tratam de algumas "táticas de intervenção" da "performatividade crítica": a resistência seletiva, as heterotopias e as microemancipações. A resistência seletiva aborda a necessidade de um alinhamento tático do CMS com as formas de resistência existentes nas organizações, uma vez que estas desenvolvem críticas das práticas gerenciais. Embora tal tática possa sugerir uma inserção política, se considerarmos um contexto de "gerencialismo engajado", como seria possível evitar que essas formas de resistência sejam cooptadas pelos interesses do management? Talvez, a principal falha de Spicer, Alvesson e Kärreman (2007) seja sugerir a possibilidade de uma "performatividade crítica" a partir da premissa de que as ações dos envolvidos seriam desinteressadas e isentas de ideologia, descartando, paradoxalmente, através de um suposto posicionamento crítico, a própria concepção de poder e o caráter político das organizações.

Quando abordam as heterotopias, os autores reafirmam sua posição reformista, na medida em que sugerem a substituição das utopias por essas heterotopias, argumentando que uma utopia significa um "não lugar" e uma heterotopia, "outros lugares", de modo que esta escaparia do idealismo da primeira, visto que se aproxima de uma posição mais realista e pragmática. A utopia, entretanto, pode remeter tanto a um cenário possível, mas não realizado, quanto servir de ferramenta teórica para análise do presente (ou mesmo a ambos), que tem uma dupla face de positividade e de negatividade.

É verdadeiro, uma vez que faz parte da existência efetiva dos homens e falso, na exata medida em que nega a esses mesmos homens a possibilidade de viverem como tais, imbricada de contradições, apesar destas serem ocultadas pelas forças dominantes da sociedade. Assim, ao rejeitarem tais características do pensamento utópico, Spicer, Alvesson e Kärreman (2007) estabelecem uma ruptura com o próprio edifício da crítica, num sentido clássico, crítica essa baseada em correntes filosóficas idealistas que têm na utopia seu ponto de partida e também de chegada. Ao invés de estabelecerem uma relação dialética entre o idealismo e o mundo real, como faria a tradição marxista, eles decidem descartar o idealismo como este fosse um posicionamento ingênuo, aproximando-se, mesmo que involuntariamente, de uma visão utilitarista.

Quanto à microemancipação, os autores acreditam que as organizações contemporâneas oferecem uma miríade de opções para a emancipação em pequena escala, sendo possível criar nessas organizações, espaços de autonomia contra as relações institucionalizadas de poder, visto que, frequentemente, é limitado o espaço para revoluções de larga escala que abalem radicalmente as estruturas de dominação e as estratégias do mundo dos negócios Não negamos a existência e a importância dessas microrresistências, mas defendemos que elas não fazem sentido fora do contexto de uma mudança no sentido sistêmico que transcenda as meras subversões individuais e grupais, reconstituindo a noção de coletividade e de esfera pública. Por outro lado, Spicer, Alvesson e Kärreman (2007) sabotam a própria ideia pós-estruturalista de resistência, na medida em que abrem espaço para um uso ideológico da mesma, sugerindo, mesmo indiretamente, que esta pode ser uma via para um "gerencialismo engajado".

\section{Discussão: caminhos para a prática na crítica}

Reddy (2007) segue em outra direção. Faz uma crítica contundente do CMS, questionando não apenas sua tentativa de se definir como "movimento político e social", mas também indagando qual sua contribuição para superar (ou mesmo modificar) o capitalismo global e as práticas gerenciais que o sustentam. Na sua visão, não há evidências de que o CMS seja responsável por uma mobilização consistente de oposição ao management corporativo, nem de que se arrisque para resistir à autoridade constituída. Embora avalie, assim como de Spicer, Alvesson e Kärreman (2007), que os acadêmicos do CMS estão comprometidos com o produtivismo e a 
sustentação de suas carreiras nas escolas de negócios, não se vale dessa mesma argumentação para defender que seria coerente esses "acadêmicos performáticos", se deslocarem para uma "performatividade crítica".

Reddy contraria o posicionamento de Spicer, Alvesson e Kärreman (2007), baseando sua crítica num contraponto entre a vida acadêmica e a militância, recuperando a oposição entre teoria e práxis. Assim, volta a politizar o debate sobre a ação dos intelectuais, permitindo-nos resgatar as diferenças entre o posicionamento dos marxistas clássicos e o dos marxistas ocidentais, tema amplamente discutido por Anderson (2004). A discussão sobre o afastamento da vida política é uma constante quando se aborda a teoria crítica, frequentemente acusada de restringir-se à teoria, com intelectuais trancados em seus gabinetes, apartados da vida política e imbuídos de uma postura elitista, na medida em que desfrutam de uma confortável vida intelectual e produzem textos inacessíveis à maioria das pessoas.

O que frequentemente é omitido é que os representantes da Escola de Frankfurt, por exemplo, viveram em uma época de opressão fascista, na qual mesmo os partidos de esquerda costumavam cercear a liberdade de expressão dos intelectuais quando estes ousavam criticar o teor de algumas práticas ditas revolucionárias. De certa forma isso desestimulou a relação dos marxistas ocidentais com o movimento revolucionário, ao contrário do ocorrido com os marxistas clássicos, que estavam visceralmente ligados às lutas políticas Assim, se por um lado o afastamento da práxis foi uma forma que os marxistas ocidentais encontraram de preservar sua autonomia para criticar o socialismo burocrático soviético, por outro, os textos herméticos os protegiam da perseguição política (ANDERSON, 2004).

Outro ponto que merece discussão é a ideia do "fazer acadêmico como prática", que remete à antiga oposição entre teoria e prática. Em primeiro lugar, é importante destacar que vivemos numa época de persistente preconceito em relação à teoria e de busca desenfreada por ferramentas e técnicas que sejam de utilidade na vida cotidiana (características ainda mais acentuadas no mundo do management). Frequentemente se esquece que a prática não existe sem a teoria, uma vez que esta é uma tentativa sistematizada de explicar e compreender a realidade, que gera conceitos a partir dos quais é possível apreender o mundo real. É a partir do saber provindo da experiência - ou seja, do empirismo científico, que nada mais é que a observação mediada pelas teorias - que se realiza a prática e são produzidas as técnicas.

Isso é claramente perceptível quando se trata das ciências naturais, nas quais a relação entre ciência e tecnologia se impõe como uma realidade, mas não é verdadeiro quando se trata das ciências humanas, cujos fenômenos não são autoevidentes, uma vez que a práxis social está incrustada nas ideologias. Nesse caso, a prática é derivada de experiências ideologicamente direcionadas, de modo que somente a observação das mesmas a partir de diferentes perspectivas teóricas é capaz de apontar alternativas de ação. Em outras palavras, sem uma avaliação crítica da realidade social, não é possível transformar suas práticas. Essa talvez seja a melhor resposta para a pergunta: "Para que serve a crítica?" Também podemos responder a isso recorrendo à célebre citação de Marx (2001, p.46): "A crítica colheu nas algemas as flores imaginárias, não para que o homem suporte as amarras sem cuidado ou conforto, mas para que lance fora as algemas e colha a flor viva".

Dessa forma, há uma importância fundamental no trabalho acadêmico realizado, especialmente, o crítico, pois é a produção de teorias e a observação da realidade através delas que pode oferecer aos ativistas e militantes políticos opções práticas ao mundo real existente. É muito provável que a propalada paralisia política contemporânea seja uma demonstração do imobilismo teórico que acometeu os intelectuais a partir da crise dos paradigmas de transformação social. Por esse motivo é essencial que se retome as antigas tradições teóricas e filosóficas, tendo em vista a produção de novas leituras e teorias. É interessante, então, que se retome a ideia de que teoria e prática estão imbricadas uma na outra, evitando-se a clivagem imposta pelo paradigma teórico dominante de que ambas consistem em momentos separados do trabalho do intelectual.

Quanto ao imobilismo político dos intelectuais - no que se refere à sua falta de inserção nas lutas políticas -, é preciso considerar o contexto histórico em que ocorre. Em tal contexto, as condições materiais apontam para um desencantamento com as possibilidades revolucionárias e uma institucionalização dos movimentos sociais, transformados em parceiros do Estado, com os antigos ativistas deslocando-se da esfera da mobilização para a 
esfera da cogestão e da atuação em organizações não-governamentais. Nesse sentido, hoje, não há mais uma preocupação com a autonomia intelectual, e os pesquisadores estão sujeitos a uma constante pressão por produtividade, sem contar que, no caso brasileiro também são impelidos a assumirem diversas atividades extras para complementar sua renda. $\mathrm{O}$ resultado é uma exiguidade de tempo e energia que reforça o afastamento das atividades políticas.

Se, por um lado, essa busca pela afirmação na carreira pressupõe alienação, por outro, não podemos deixar de notar que essa alienação resulta do caráter opressivo e competitivo do ambiente onde os pesquisadores estão inseridos. Nessas condições, fazer um trabalho crítico pode soar como manifestação de uma "consciência cínica", embora também não deixe de ser uma das poucas vias que restaram para alguma subversão. Além disso, talvez seja mais interessante dar vazão à manifestação de uma "consciência cínica" do que de uma "consciência feliz" (MARCUSE, 2002), aceitando que o real é racional ou que tudo é discurso e que não há mais lugar para a razão crítica.

Por outro lado, a inserção do intelectual na vida política não é uma questão de simples resolução. Esse problema foi amplamente discutido no fórum "O silêncio dos intelectuais" realizado pelo Ministério da Cultura em várias capitais brasileiras em 2005, com participação de importantes intelectuais contemporâneos. No evento, cujas conferências estão disponíveis para escuta na internet e sintetizadas no livro de Novaes (2006), resgatou-se tanto a polêmica entre Adorno e Marcuse por ocasião do movimento estudantil de 1968, como as críticas que Sartre recebeu por ter colaborado com a Revolução Cultural chinesa. No caso de Adorno e Marcuse, o primeiro criticou o que considerava o caráter autoritário do movimento estudantil - inclusive, chamando forças policiais para que os estudantes desocupassem a universidade -, enquanto o segundo tentou convencer os estudantes de que deveriam utilizar uma abordagem mais democrática.

Adorno e Marcuse trocaram cartas sobre suas discordâncias e após a morte de Adorno, Marcuse declarou que compreendia o amigo, pois seu afastamento da prática política se deu por considerar que não estavam colocadas as condições históricas adequadas para uma verdadeira revolução. Sobre isso Marcuse declarou: "Na sua opinião [opinião de Adorno], ações sem qualquer base social não podem igualmente ter força social, não são expressão de esperança, mas de desespero, e podem facilmente tornar-se um joguete nas mãos do inimigo" (MARCUSE citado por LOUREIRO, 1999, p.106). No caso de Sartre, Silva (2005) afirma que sua aproximação como militante da Revolução Chinesa resultou num grande preconceito em relação aos seus escritos - que foram simplesmente abandonados -, mas que deveriam ser recuperados, uma vez que um erro de escolha de posicionamento político não deveria invalidar as teorias de um intelectual.

Dessa forma, mais uma vez, comprovamos que o afastamento dos intelectuais da vida política não pode se interpretado meramente como comodismo, pois também envolve posicionamentos ideológicos e escolhas que, inclusive, podem comprometer a credibilidade das teorias formuladas. É importante ainda não esquecer que, se há uma tarefa crítica na qual esses pesquisadores devem se engajar, certamente, é a educação, que não deixa de ser caminho para a reconstituição de outra importante tarefa crítica: o ativismo político e social. Por mais que o ambiente de uma escola de business seja opressor, as práticas formativas ainda podem ser uma saída para estimular a reflexividade e mudar a mentalidade da classe dirigente. Por outro lado, sem o despertar da consciência crítica, não há como fomentar nenhuma forma de ativismo.

O CMS (ADLER; FORBES; WILLMOTT, 2007) não deixa de apontar a importância dessas tarefas críticas. No entanto, ao defender relação com a prática gerencial cotidiana como um projeto crítico, abre espaço para pactuar com o comportamentalismo vulgar dos programas de qualidade de vida no trabalho, de motivação e liderança, de qualidade total e de mudança organizacional, entre outras estratégias integracionistas. Se a intenção é apaziguar a "consciência cínica" de quem faz a crítica vendo o mundo a partir de sua mesa de trabalho, a via não pode ser o colaboracionismo com as práticas gerenciais. O pesquisador deve estar consciente de que sua prática como gerente e consultor precisa ser tratada reflexivamente e de acordo com a sua realidade material e ideológica, pois o "gerencialismo engajado", longe de se revelar uma prática libertária, constitui-se apenas em autoengano. 


\section{Conclusões}

Os autores críticos do campo da administração têm buscado agrupar-se para legitimar a área de crítica como espaço acadêmico, através da consolidação de suas linhas de pesquisa e também como movimento político. O CMS, do todos os fóruns de crítica discutidos neste artigo, é o que tem se organizado de maneira mais efetiva na busca da integração entre as diversas correntes da crítica. Ele tem sido compreendido, portanto, como um fórum político de legitimação da área de crítica nas escolas de business. Isso ajuda a explicar a agregação de estudiosos frankfurtianos, pós-estruturalistas, marxistas, interpretativistas, etnólogos etc. Alguns de seus representantes, porém, têm consciência de que, quanto mais caminharem para a legitimação da área - o que significa mais espaço, autonomia e respeito nas universidades (por consequência, também maior acesso a recursos financeiros e institucionais) -, maior o risco da crítica perder seu foco, podendo ser incorporada pela lógica da racionalidade.

Muitos deles aceitam o pluralismo no movimento CMS. Parker, por exemplo, um dos principais autores dessa linha de pesquisa, possui trabalhos críticos derivados de diversas correntes epistemológicas, desde o humanismo radical até as visões pós-modernas. Dessa forma, podemos perceber que a defesa do pluralismo epistemológico nada teria a ver com o descompromisso com a crítica, se somente fossem consideradas as atividades políticas na prática como demonstração de alinhamento com a crítica. Porém, conforme buscamos discutir neste artigo, o pluralismo epistemológico tem implicações no campo da teoria e tem sido utilizado por diversos pesquisadores como justificativa para o desmantelamento do projeto dos estudos críticos em administração. O conformismo e a falácia da performatividade crítica são exemplos do que aqui denominamos "gerencialismo engajado".

É importante ressaltar que essa perspectiva não é fruto de uma perspectiva epistemológica específica. Ela advém do mau uso da teoria. Ainda que tenhamos apontado aspectos pós-estruturalismo que levem ao questionamento de seu comprometimento com a crítica, não podemos deixar de notar que o mesmo tem sido utilizado, muitas vezes, de forma caricatural. Além disso, poucos são os estudos que, de fato, aprofundam uma discussão sobre seu projeto original e suas relações com o estruturalismo, que é outra perspectiva teórica que deveria ser analisada com mais seriedade. Por esse motivo, acreditamos que o pós-estruturalismo deveria ser revisto, de modo que suas contribuições fossem incorporadas, mas o caráter crítico preservado, fundando um novo movimento teórico, caso fosse necessário.

A apropriação indevida de conceitos, infelizmente, é uma prática recorrente em nosso campo de estudos. Um exemplo recente disso é o artigo de Zyman, "O marketing e Karl Marx" (2005), que demonstra claramente as possíveis utilizações da "performatividade crítica". Segundo este autor, Karl Marx e seu parceiro Friedrich Engels deveriam servir de inspiração para os administradores, pois o Manifesto comunista seria uma demonstração de como eles trataram o comunismo como uma "oportunidade de marketing". Estas são as conclusões do autor:

Eles viram nisso uma oportunidade de vendas! [...] Espelhando-se nisso, os gerentes de marketing devem se basear no Manifesto Comunista e criar seu Manifesto de Marketing, capaz de galvanizar e unir seus funcionários. Dizer a eles para onde ir e os ajudar a concentrar suas energias. (ZYMAN, 2005, p.34)

Contra o uso inadequado de uma teoria e sua deturpação, o que se pode fazer é não naturalizar a discussão, mantendo-a viva nos fóruns acadêmicos adequados, a fim de buscar a reflexividade dos pesquisadores acerca dos usos feitos de determinados conceitos. Por outro lado, a discussão da relação entre teoria e prática no movimento crítico precisa ter como referência o conceito de práxis, bem como basear-se na noção de que a educação é a única via possível para a mudança e para o resgate do ativismo social e político. Esperamos que este artigo possa contribuir para esse debate e gerar novas oportunidades de avaliação e balanço do movimento crítico no Brasil e no mundo. 


\section{Referências}

ADLER, P. S.; FORBES, L. C.; WILLMOT, H. Critical management studies: premises, practices, problems, and prospects. Paper presented at Academy of Management Annual Meeting, Philadelphia, 2007.

ADORNO, Theodor W. Educação e emancipação. Rio de Janeiro: Paz e Terra, 2003.

; HORKHEIMER, M. Dialética do esclarecimento: fragmentos filosóficos. Rio de Janeiro: Jorge Zahar Editor, 1985.

ALCADIPANI, R. Réplica: a singularização do plural. Revista de Administração Contemporânea, v.9, n.1, p.213-222, jan./mar. 2005.

ALVESSON, M.; WILLMOT, H. On the idea of emancipation in management and organization studies. Academy of Management Review, v.17, n.3, p.432-464, 1992a.

Critical management studies. London: Sage, $1992 \mathrm{~b}$.

(Org.). Making sense of management: a critical analysis. London: Sage, 1993.

ANDERSON, P. Considerações sobre o marxismo ocidental. Nas trilhas do materialismo histórico. São Paulo: Boitempo Editorial, 2004.

CLEGG, S. et al. For Management? Management Learning, v.37, n.1, p.7-27, 2006.

D'AGOSTINI, F. Lógica do niilismo. Dialética, diferença e recursividade. São Leopoldo: Editora Unisinos, 2002.

FORESTER, J. Critical theory and organizational analysis. In: MORGAN, G. (Ed.) Beyond method. Beverly Hills, CA: Sage, 1983.

FOURNIER, V.; GREY, C. Na hora da crítica: condições e perspectivas para estudos críticos de gestão. Revista de Administração de Empresas, v.46, n.1, p. 71-86, jan./mar. 2006.

FREIRE, Paulo. A importância do ato de ler: três artigos que se completam. São Paulo: Cortez, 1989.

HABERMAS, J. 0 discurso filosófico da modernidade. Lisboa: Dom Quixote, 1990.

HASSARD, J. From labor process theory to critical management studies. Administrative Theory \&t Praxis, v.23, n.3, p.339-362, 2001.

JAROS, S. J. Marxian critiques of Thompson's (1990) 'core' labour process theory: an evaluation and extension. Ephemera, v.5, n.1, p.5-25, 2005.

KNIGHTS, D. Hanging out the dirty washing: labour process theory in the age of desconstruction. Paper presented at $13^{\text {th }}$ Labour Process Conference, Blackpool, 1995.

LOUREIRO, I. Herbert Marcuse: a grande recusa hoje. Petrópolis, RJ: Vozes, 1999.

MARCUSE, H. Eros e civilização: uma interpretação filosófica do pensamento de Freud. Rio de Janeiro: Zahar Editores, 1978.

One dimensional man: studies in the ideology of advanced industrial society. London: Routledge, 2002.

MARX, K. Contribuição à crítica da filosofia do direito de Hegel. In: MANUSCRITOS econômico-filosóficos. São Paulo: Martin Claret, 2001.

McGUSHIN, E. Foucault and the problem of the subject. Philosophy \& Social Criticism, v.31, n.5-6, p.623-648, 2005.

MISOCZKY, M. C.; AMANTINO-DE-ANDRADE, J. Uma critica à crítica domesticada nos estudos organizacionais. Revista de Administração Contemporânea, v.9, n.1, p.193-211, jan./mar. 2005a.

Tréplica: Quem tem medo do fazer acadêmico como práxis? Revista de Administração Contemporânea, v. 9, n.1, p.239245, jan./mar. 2005b.

NOVAES, A. (org.) 0 silêncio dos intelectuais. São Paulo: Companhia das Letras, 2006.

O'DOHERTY, D.; WILLMOT, H. The question of subjectivity and the labour process. International Studies of Management and Organization, v.30, p.112-131, 2001. 
PARKER, M. Critique in the name of what? Postmodernism and critical approaches to organization. Organization Studies, v.16, n.4, p.553-564, 1995.

. Capitalism, subjectivity and ethics: debating labour process analysis. Organization Studies, v.20, n.1, p.25-45, 1999.

Against management: organization in the age of managerialism. Cambridge: Polity Press; Blackwell Publishers, 2002. Stockholm syndrome. Management Learning, v.37, n.1, p.39-41, 2006.

REDDY, P. Against academic activism: or, why does the revolution need academics anyway? Paper presented at $5^{\text {th }}$ Critical Management Studies Conference, Manchester, 2007.

SILVA, F. L. 0 imperativo ético de Sartre. Conferência proferida para o ciclo de debates "0 silêncio dos intelectuais". 2005. Disponivel em: $<$ <ttp://www.cultura.gov.br/foruns_de_cultura/cultura_e_pensamento/conferencias/index.php?p=10494\&tmore=1\&tc=1\&tpb=1>. Acesso em: 16 mar. 2008.

SMITH, C.; THOMPSON, P. When Harry met Sally... and Hugh and David and Andy: a reflection on ten years of the labour process conference. Paper presented at the $10^{\text {th }}$ Labour Process Conference, Aston, 1992.

SPICER, A.; ALVESSON, M.; KÄRREMAN, D. Critical perfomativity: the unfinished business of critical management studies. Paper presented at $5^{\text {th }}$ Critical Management Studies Conference, Manchester, 2007.

STEFFY, B.; GRIMMES, A. A critical theory of organization science. Academy of Management Review, v.11, p.322-336, 1985.

THOMPSON, P.; ACKROYD, S. All quiet on the workplace front? A critique of recent trends in British Industrial Sociology. Sociology, v.29, n.4, p.615-633, 1995.

WATSON, T. J. In search of management. London: Thomson Learning, 2001.

WILLMOT, H. From bravermania to achizophrenia: the dis(is/ec)cased condition of subjectivity in labour process theory. Paper presented at $13^{\text {th }}$ Labour Process Conference, Blackpool, 1995.

WILLMOT, H. Pushing at an Open Door: Mystifying the CMS Manifesto. Management Learning, v.37, n.1, p.33-37, 2006

ZYMAN, S. 0 marketing e Karl Marx. HSM Management, v.5, n.52, p.68-79, set./out. 2005. 